\title{
Interesses profissionais de jovens de ensino médio: estudo correlacional entre a escala de aconselhamento profissional e o self-directed search carrier explorer
}

\author{
Professional interests of high school students: a \\ correlational study between the escala de \\ aconselhamento and self-directed \\ search career explorer
}

\author{
Fernanda Argentini SARTORI \\ Ana Paula Porto NORONHA \\ Silvia GODOY2 \\ Rodolfo Augusto Matteo AMBIEL ${ }^{3}$
}

\begin{abstract}
Resumo
O estudo de instrumentos de avaliação psicológica no contexto de orientação profissional é de fundamental importância, pois favorece maior confiabilidade e enriquecimento da interpretação dos resultados. A presente pesquisa objetivou explorar as correlações entre as dimensões da Escala de Aconselhamento Profissional e as seções Competências, Carreiras e Habilidades do Self-Directed Search Career Explorer. A Escala de Aconselhamento Profissional é um instrumento que avalia as preferências por atividades profissionais e o Self-Directed Search Career Explorer traça o perfil tipológico dos interesses dos indivíduos. Participaram do estudo 132 estudantes (54,5\% mulheres), com idade média de 15,9 anos, que cursavam o ensino médio de escolas particulares do interior paulista. Os resultados apresentaram correlações significativas $(p \leq 0,05)$ entre alguns tipos do Self-Directed Search Career Explorer e dimensões da Escala de Aconselhamento Profissional teoricamente relacionadas, tais como tipo Artístico com a dimensão Artes e Comunicação. Outras pesquisas devem ser desenvolvidas a fim de contribuir com estudos de outros instrumentos.
\end{abstract}

Unitermos: Avaliação psicológica. Interesse profissional. Orientação ocupacional.

\begin{abstract}
The study of instruments of psychological assessment in the context of vocational guidance is of fundamental importance, since it provides a greater reliability and enriches the interpretation of the results obtained. This research explored the correlation between the dimensions of

४

1 Universidade São Francisco, Programa de Pós-Graduação Stricto Sensu em Psicologia. R. Alexandre Rodrigues Barbosa, 45, Centro, 13251-900, Itatiba, SP, Brasil. Correspondência para/Correspondence to: A.P.P. NORONHA. E-mail: <ana.noronha@saofrancisco.edu.br>.

2 Doutoranda, Universidade Presbiteriana Mackenzie, Programa de Pós-Graduação Stricto Sensu em Distúrbios do Desenvolvimento. São Paulo, SP, Brasil.

3 Universidade São Francisco, Curso de Psicologia. Itatiba, SP, Brasil.
\end{abstract}


the escala de aconselhamento profissional and the sections Skills, Careers and Abilities of the Self-Directed Search Career Explorer. The Vocational Advice Scale is an instrument that evaluates the preferences for vocational activities and the Self-Directed Search Career Explorer draws the typological profile of the individuals' interests. The participants included 132 students (54.5\% were women), with average age of 15.9 years, attending private High Schools in São Paulo state. The results demonstrated significant correlations ( $p \leq 0.05$ ) between some types of Self-Directed Search Career Explorer and the escala de aconselhamento profissional dimensions. Further research should be developed in order to contribute to studies on new or existing instruments.

Uniterms: Psychological assessment. Occupational interests. Occupational guidance.

A escolha de uma profissão, de acordo com Silva (1999), tende a relacionar-se com diversos fatores, tais como a internalização do meio social no qual o jovem se desenvolveu e a imposição, por parte da sociedade, de que ele deva consolidar uma identidade profissional na adolescência, ainda que em muitos casos isso aconteça numa fase mais tardia do desenvolvimento. A Orientação Profissional (OP), sob essa perspectiva, tem por finalidade acolher os indivíduos em suas inquietações no que se refere à carreira profissional, avaliando as características do sujeito e auxiliando-o a traduzir essas características em boas escolhas profissionais, comparando-as com informações sobre as diferentes áreas. Em acréscimo, a OP incentiva a exploração das possibilidades de escolhas, tal como preconizado por Holland (1977) e Savickas (1999).

Segundo Sparta (2003), a atuação em OP é resguardada, no Brasil, para psicólogos e pedagogos, embora não haja qualquer lei que regulamente e normatize os conteúdos básicos ensinados em cursos de formação. Em consequência disso, a autora ressalta que o não reconhecimento da área como especialidade do psicólogo (Resolução 014/00 do Conselho Federal de Psicologia) favorece que profissionais atuem sem formação específica. Em que pesem tais considerações, no contexto brasileiro, a OP vem sofrendo algumas transformações a fim de apresentar um campo teórico mais fortalecido e uma área de aplicação mais consistente (Noronha \& Ambiel, 2006).

Como ponderam Teixeira e Lassance (2006), processos de OP têm sido considerados relevantes diante das dificuldades de decisão profissional quando realizados de forma consistente, com métodos e técnicas científicas. Para tanto, a utilização de testes psicológicos validados e precisos, construídos ou adaptados para populações em situações específicas, tais como a OP, se faz necessária na medida em que os resultados e a eficácia da intervenção podem, assim, ser avaliados com relação aos objetivos propostos.
Os instrumentos de avaliação psicológica têm como premissa a existência de diferenças individuais e, nesse particular, Anastasi e Urbina (2000) destacam que tais diferenças contribuem, por exemplo, para a construção de inventários que explorem os interesses dos indivíduos, sendo possível investigar a relação dos interesses de alguns indivíduos aos de pessoas que têm sucesso em determinadas ocupações, bem como relacionar os interesses com outros construtos psicológicos. Para as autoras, pessoas dedicadas às mesmas ocupações caracterizam-se por interesses comuns que as diferenciam das pessoas de outras ocupações, de tal forma que as diferenças de interesse estendem-se não apenas a questões diretamente ligadas a ocupações profissionais, como também a matérias escolares, passatempos, esportes e literatura em geral.

Dentre os construtos psicológicos investigados nos processos de orientação profissional, destaque deve ser dado aos interesses profissionais. Noronha e Ambiel (2006), ao estudarem a literatura científica brasileira, encontraram dados que indicaram a predominância de estudos relacionados aos interesses em relação a outros construtos, tais como personalidade e inteligência. No contexto estrangeiro, Guindon e Richmond (2005) encontraram dados que apontaram na mesma direção, reafirmando o maior número de pesquisas com esse construto.

Quanto ao estudo teórico do interesse, Leitão e Miguel (2001) relatam que alguns autores dedicados ao tema partiram de abordagens empíricas, centradas em definições conducentes à identificação de aspectos básicos de interesses a serem avaliados. Sob essa perspectiva, organiza-se um conjunto de itens que se agrupam em escalas para discriminar algumas categorias básicas de interesse profissional entre determinados grupos, baseando-se em critérios estatísticos de comparação profissionais. Em contrapartida, há um menor número de autores que optaram por uma abordagem a priori, partindo de uma teoria existente para a constru- 
ção de itens que, de acordo com conceitos determinados e agrupados, permitem testar os pressupostos teóricos em questão.

Quanto à definição dos interesses, Leitão e Miguel (2004) afirmam que ainda há muita controvérsia por não haver uma concordância teórica a esse respeito. Santos (1997) assinala que na base dos interesses encontram-se diversos fatores, tais como necessidade de realização, reconhecimento social, motivos econômicos, autoestima, sugestões e valores do grupo social e familiar, dentre outros. Para o autor, um processo de OP, levando em conta os interesses dos participantes, tende a promover o desenvolvimento humano por meio de uma estratégia conjunta de desafio e apoio, constituindo, assim, um avanço no plano teórico e nas implicações para a intervenção.

Pelletier, Bujold e Noiseux (1985) sugerem que o interesse por uma profissão relaciona-se com o processo de construção da identidade e que quando um jovem não tem clareza disso, questiona-se, frequentemente, sobre sua competência para a escolha. Nesse sentido, quando a identidade não está estruturada, os autores acreditam que os interesses tendam a se diversificar e que a escolha por uma profissão se torne ainda mais angustiante. Ao lado disso, outra situação pode estar presente: a ausência de interesses que se destaquem e que funcionem como facilitadores do processo de decisão.

De acordo com Leitão e Miguel (2004), a teoria que melhor integra as ideias concernentes ao construto interesse é a de Savickas (1999). Nessa definição, o interesse é uma tendência para a satisfação de necessidades e valores pessoais, razão pela qual o último autor descreve esse conceito como sendo a prontidão de resposta a estímulos ambientais específicos (objetos, atividades, pessoas ou experiências).

Savickas (1999) afirma que os interesses são fruto de um processamento cognitivo acompanhado de emoções que se transformam em volição, a qual determina a ação com intuito de promover interações sujeito-ambiente, integrando, numa relação vital, sujeito, objeto e comportamento. Dessa forma, manifesta-se em ações que satisfazem necessidades e valores que promoverão o desenvolvimento pessoal, aumentando a adaptação ao contexto e a consolidação da identidade. Em suma, de acordo com esse autor, compreende-se interesse como o resultado de um processamento cognitivo gerador de emoções e volição, que constituem os determinantes das interações sujeito-ambiente.

No Brasil, Noronha, Sisto e Santos (2007) corroboraram a visão do autor supracitado e, baseando-se em suas definições, desenvolveram a Escala de Aconselhamento Profissional (EAP). Os autores do instrumento propuseram-se a pesquisar a caracterização das preferências dos estudantes por determinadas atividades profissionais, buscando evidência de validade de construto por meio da investigação da estrutura interna. Participaram dessa pesquisa, 762 estudantes universitários (59\% mulheres) na faixa etária entre 17 e 73 anos, com média de 24,14. Os resultados da análise fatorial sugeriram uma solução de sete dimensões, a saber: Ciências Exatas, Artes e Comunicação, Ciências Biológicas e da Saúde, Ciências Agrárias e Ambientais, Atividades Burocráticas, Ciências Humanas e Sociais Aplicadas e Entretenimento, com índices de saturação superiores a 0,30 e variância explicada de 57,3\%, que permitiram rastrear as atividades prioritariamente escolhidas pelos participantes da amostra do estudo.

No mesmo estudo, os autores realizaram análises que atribuíram evidências de validade de critério ao instrumento ao comparar as médias dos participantes em cada dimensão com as médias de seus respectivos cursos. Assim, buscou-se perceber em que medida as atividades profissionais listadas como preferidas pelos estudantes se relacionavam às médias obtidas, em cada dimensão da EAP, pelo seu curso. De forma geral, os cursos se destacaram em dimensões relacionadas às suas atividades, ainda que carreiras diferentes tenham se aproximado em algumas dimensões não tão próximas quanto às atividades típicas. Com relação à precisão, os valores de alfa de Cronbach ficaram entre 0,79 e 0,94 e os de Spearman-Brown e Guttman entre 0,75 e 0,91, atestando uma boa consistência interna.

Outra abordagem dos interesses profissionais, utilizada e estudada em todo o mundo, é a de Holland (1963), que afirma que as pessoas procuram ambientes profissionais congruentes com suas orientações pessoais. Em trabalho posterior, Holland, Fritzsche \& Powell (1994) propuseram que as pessoas aprendem a gostar mais de certas atividades do que de outras, o que pode ser explicado pelas tendências motivacionais. 
A proposta teórica de Holland (1963) consiste na apresentação de seis tipos de personalidade e ambientes laborais, tendo cada um características próprias de interesses, habilidades e competências. Gati (1991) destaca que os tipos de personalidade indicados por Holland são representados visualmente em um hexágono, sendo um dos mais conhecidos e respeitados no contexto da orientação às carreiras profissionais. Vale ressaltar que a disposição dos tipos foi estabelecida a partir de estudos correlacionais entre os respectivos escores e a posição ocupada, sugerindo a maior proximidade das características mais comuns.

Os seis tipos propostos por Holland (1996) são descritos a seguir. O Realista (R) descreve pessoas mais voltadas para realizações observáveis e concretas, tendendo a ser pouco sociáveis, com boa coordenação motora e rapidez, com valores políticos e econômicos convencionais, além de se perceberem como agressivos. O Investigativo (I) é mais introvertido e voltado à exploração intelectual, optando por pensar a agir; prefere profissões como química, botânica, zoologia, medicina, entre outras. O Artístico (A) tende a ser mais associal, como o tipo Investigativo, porém mais emotivo e envolvido com atividades que favoreçam a expressão individual; prefere trabalhar como ator, músico, poeta, escritor e artista. O Social (S) descreve pessoas mais extrovertidas e dependentes que gostam de atividades de ajuda, ensino, tratamento e que têm maior necessidade de atenção; tendem a possuir capacidade verbal e interpessoal e preferem as profissões como psicólogo, professor, pedagogo e orientador.

Por sua vez, o Empreendedor (E) descreve pessoas mais oralmente agressivas, cuja preferência é voltada às atividades nas quais possam dominar, persuadir e liderar os outros. Os indivíduos empreendedores preferem trabalhar como administrador, acionista, vendedor e comerciante. Por fim, o Convencional (C) descreve pessoas mais conformistas e controladas, que se destacam em atividades estruturadas que envolvam obediência às ordens e às regras; identificam-se com o poder, valorizando os bens materiais e a posição social. Preferem profissões como economista, contador, estatístico, caixa e policial.

Conforme a concepção teórica apresentada e com a finalidade de avaliar os interesses profissionais, Holland (1977) construiu o Self-Directed Search Career
Explorer (SDS), dividido em quatro seções - Atividades, Competências, Carreiras e Habilidades - compostas por itens representativos da tipologia de Holland. Como o instrumento foi construído para viabilizar uma autoavaliação, o próprio sujeito pode contar suas respostas, chegando ao chamado Código de Holland, que corresponde aos dois tipos com maiores pontuações.

Nesse ensejo, vale destacar o estudo de validação do SDS realizado por Mansão (2005), do qual participaram 1162 estudantes do ensino médio. A autora correlacionou os tipos do SDS com as áreas do teste Levantamento de Interesses Profissionais (LIP), e obteve resultados com correlações significativas. No tipo Realista, as correlações foram significativas com relação às áreas das Ciências Físicas (CF) e do Cálculo (C), enquanto o tipo Investigativo correlacionou-se com as áreas Ciências Biológicas (CB) e Ciências Físicas (CF). No que toca ao tipo Artístico, as correlações mais significativas foram com as áreas Artística (A), Linguística (L) e Social (S) e o tipo Social apresentou correlação significativa com a área de interesses Ciências Biológicas (CB). O tipo Empreendedor obteve correlações negativas com a área Ciências Biológicas (CB) e positivas com Burocrática Administrativa (BA) e Persuasiva (P). Por fim, o tipo Convencional correlacionou-se com as áreas Burocrática Administrativa e Cálculo.

Com relação à validade, a análise fatorial indicou a existência de seis fatores teoricamente compatíveis com os tipos profissionais de Holland. No que toca à precisão, a consistência interna das escalas foi boa, variando entre 0,87 e 0,90 e o teste-reteste demonstrou que o instrumento apresenta boa estabilidade temporal, com bons índices de correlação, variando entre 0,82 e 0,91 .

Numa outra pesquisa com amostra brasileira, Primi, Moggi e Casellato (2004) buscaram correlações da versão brasileira do Self Directed Search (SDS) com o Inventário Fatorial de Personalidade (IFP), a partir da aplicação dos instrumentos em 81 adolescentes, dos quais $78 \%$ eram mulheres. Os participantes tinham idade entre 16 e 17 anos e participavam de um programa de OP oferecido por uma universidade do interior paulista. Os resultados apresentaram correlações significativas entre os traços de personalidade do IFP com os tipos de Holland: o Realista com o traço Heterossexualidade; os tipos Social e Artístico com Assistência e Desejabilidade; 
o Empreendedor com os traços Dominância, Desempenho, Exibição, Agressão, Autonomia, Heterossexualidade e Ordem e, por fim, o tipo Convencional, com o traço Persistência.

Vale ressaltar, ainda, o estudo de Nunes (2007) com 289 estudantes da primeira à terceira série do ensino médio (56,0\% do sexo feminino), com média de 16 e desvio-padrão de 0,9 anos -, que teve como um dos objetivos investigar algumas características do SDS. Quanto à frequência em que as tipologias do SDS tiveram médias mais altas, observou-se que os tipos com escores mais elevados foram o Empreendedor (28,7\%), seguido pelo Social $(21,1 \%)$, e os que obtiveram escores gerais mais baixos foram o Realista $(8,0 \%)$ e o Convencional (9,0\%). A autora encontrou diferenças de média em função da variável gênero para os tipos Realista, Social e Convencional, obtendo os homens médias mais altas para o Realista e as mulheres para Social e Convencional.

Outros estudos buscaram pesquisar os interesses profissionais em relação a diferentes construtos. Bueno, Lemos e Tomé (2004) objetivaram avaliar as relações entre interesses, personalidade e inteligência em estudantes de psicologia por meio dos instrumentos Levantamento de Interesses Profissionais, 16 PF e Matrizes Progressivas de Raven - Escala Geral. Os autores revelaram que os interesses mais significativos apontados pelo grupo foram pela área social, ciências biológicas e literatura. Notaram, também, a ocorrência de baixos índices de interesse por atividades relacionadas às ciências físicas e ao cálculo. Os resultados indicaram que os sujeitos se diferenciam quanto aos construtos e o perfil de cada subgrupo gerado pelas análises mostrou relação entre as características avaliadas e a escolha por determinadas áreas de atuação da psicologia, permitindo inferir que embora a escolha pelo curso tenha sido a mesma, tais áreas exigem características distintas.

Melo-Silva, Noce e Andrade (2003) buscaram caracterizar a clientela de um programa de orientação profissional quanto às suas inclinações profissionais. Composta por 136 adolescentes (71\% mulheres), com idades entre 16 e 20 anos, a amostra foi submetida ao Teste de Fotos de Profissões (BBT) em suas versões masculina e feminina. O grupo feminino apresentou interesses prioritariamente caracterizados pelo cuidado com o outro, ajuda, valorização da intuição e imagi- nação criadora, comunicação e nutrição. Já o grupo masculino caracterizou-se, principalmente, por interesses que envolvem o senso social, pesquisa, dinamismo, atividades exatas e que exijam precisão.

Tendo em vista a necessidade de produção de estudos que qualifiquem instrumentos de avaliação psicológica no âmbito da OP e visando fornecer um refinamento de suas intepretações para diferentes amostras, o presente estudo visou explorar, a partir de respostas de estudantes do ensino médio, as correlações das dimensões da Escala de Aconselhamento Profissional com três das quatro seções do SDS: Competências, Carreiras e Habilidades.

\section{Método}

\section{Participantes}

Participaram da pesquisa 132 estudantes $(54,5 \%$ mulheres) de ensino médio, com idade média de 15,9 anos e desvio-padrão de 1,0. Os participantes eram provenientes de três diferentes escolas particulares de uma cidade do interior de São Paulo, sendo 47,0\% do primeiro ano, $36,4 \%$ do segundo e $15,9 \%$ do terceiro. Um participante $(0,8 \%)$ omitiu tal informação.

\section{Instrumentos}

Escala de Aconselhamento Profissional (EAP) (Noronha et al., 2007): avalia as preferências por atividades profissionais. Em um primeiro momento, a EAP foi construída a partir de 220 itens elaborados por meio das descrições de várias profissões, tomando-se como referência diferentes guias profissionais e descrições, disponíveis na Internet, dos perfis fornecidos por universidades brasileiras. Após essa etapa, procedeu-se à análise heurística dos itens pelos três autores do instrumento, que separaram os itens presentes em mais de uma profissão. O critério para a manutenção do item foi sua repetição em várias profissões. Houve, ainda, o cuidado de verificar se todas as áreas profissionais estavam representadas. Com essa redução, chegou-se a uma escala de 61 itens que mais representavam várias possibilidades profissionais e atendiam, de maneira geral, todas as áreas. Dessa forma, pretendeu-se abranger uma gama ampla de atividades. O formato da escala é Likert e as respostas vão de frequentemente (5) a nunca (1), de 
acordo com o interesse do avaliando em desenvolver cada atividade. Os estudos psicométricos constantes no manual do instrumento foram descritos na introdução do presente trabalho.

Self-Directed Search Career Explorer-SDS (Holland, 1963; Holland et al., 1994): desenvolvido com o objetivo de apoiar a identificação de características da personalidade do indivíduo, leva em conta a delimitação do ambiente ocupacional congruente com a personalidade, em função dos interesses e capacidades. É um instrumento embasado no modelo hexagonal de Holland quanto às características dos seis tipos e à natureza das interações pessoa-ambiente, sendo aplicável a populações de ensino médio e ensino superior. É estruturado em quatro seções: Atividades, Competências, Carreiras e Habilidades. Cada dimensão é composta por itens propostos por Holland, a saber: Realista (R), Investigativo (I), Artístico (A), Social (S), Empreendedor (E) e Convencional (C).

As seções Atividades e Competências são compostas por 66 itens cada uma (11 por tipo); a seção Carreira tem o total de 72 itens ( 12 por tipo) e a Habilidades, 12 (dois por tipo). À medida que o estudante responde às seções do instrumento, ele define, por meio dos resultados, as duas primeiras áreas com um maior escore de pontos que representam seu perfil de interesses.

No que se refere à verificação dos parâmetros psicométricos com amostras brasileiras, destacam-se os estudos de Mansão (2005), antes apresentados.

\section{Procedimentos}

Após aprovação do Comitê de Ética da Universidade São Francisco (Protocolo n 209/02), foi realizado contato com as escolas a fim de explicar os objetivos da pesquisa e estabelecer datas para a coleta de dados. Os participantes responderam aos testes coletivamente, em sala de aula, após a assinatura do Termo de Consentimento Livre e Esclarecido pelos seus respectivos responsáveis. Aplicou-se primeiro a EAP e, em seguida, oSDS.

\section{Resultados e Discussão}

Nesta seção, serão descritas e discutidas as estatísticas descritivas dos instrumentos utilizados em termos da frequência, pontuações mínimas e máximas, média, desvio-padrão e médias ponderadas. Também serão descritas as análises de correlação de Pearson, bem como o nível de significância de cada correlação. Vale destacar que, devido ao número desigual de itens por fator, foi necessário realizar a ponderação das médias, dividindo-se esse valor pela quantidade de itens de cada fator, sendo assim possível realizar uma comparação entre elas.

$\mathrm{Na}$ EAP, as maiores médias ponderadas foram encontradas nos fatores Atividades Burocráticas e Ciências Agrárias e Ambientais, sendo as menores médias ponderadas encontradas nos fatores Ciências Biológicas e da Saúde e Ciências Exatas (Tabelas 1 e 2).

A seção Competências teve o tipo Social com a maior média ponderada, seguida pelo tipo Empreendedor. Na seção Carreiras, o tipo Empreendedor teve a maior média, seguido por Artístico. E, por fim, na seção Habilidades, os tipos Investigativo e Artístico tiveram as maiores médias ponderadas. Esses resultados parecem não corroborar os de Nunes (2007) no que diz respeito aos achados da última seção, uma vez que os tipos Empreendedor e Social apresentaram escores mais elevados em sua pesquisa (Tabela 2).

Tabela 1. Estatísticas descritivas da escala de preferências profissionais.

\begin{tabular}{|c|c|c|c|c|c|c|c|}
\hline \multirow{3}{*}{$\begin{array}{l}\text { U } \\
\text { 꼭 } \\
\text { 음 }\end{array}$} & Dimensões & Frequência & Mínimo & Máximo & Média & Desvio-Padrão & Média ponderada \\
\hline & Ciências Exatas & 131 & 14 & 69 & 32,65 & 12,44 & 2,33 \\
\hline & Artes e Comunicação & 132 & 15 & 70 & 37,47 & 13,18 & 2,68 \\
\hline \multirow{2}{*}{$\begin{array}{l}\stackrel{D}{+} \\
\stackrel{D}{-}\end{array}$} & Ciências Biológicas e da Saúde & 132 & 8 & 44 & 21,78 & 9,49 & 2,42 \\
\hline & Ciências Agrárias e Ambientais & 132 & 13 & 58 & 35,15 & 11,83 & 2,70 \\
\hline \multirow[t]{2}{*}{ 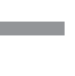 } & Atividades Burocráticas & 132 & 13 & 59 & 35,33 & 9,88 & 2,72 \\
\hline & Ciências Humanas e Sociais & 132 & 10 & 44 & 25,74 & 7,41 & 2,57 \\
\hline 220 & Entretenimento & 132 & 6 & 30 & 16,12 & 6,42 & 2,69 \\
\hline
\end{tabular}


Tabela 2. Estatísticas descritivas do Self-Directed Search Career Explorer.

\begin{tabular}{|c|c|c|c|c|c|c|}
\hline Secções & Frequência & Mínimo & Máximo & Média & Desvio-Padrão & Média ponderada \\
\hline Competência realista & 132 & 0 & 15 & 3,82 & 3,22 & 0,35 \\
\hline Competência investigativa & 130 & 0 & 11 & 5,36 & 3,48 & 0,49 \\
\hline Competência artística & 130 & 0 & 11 & 4,96 & 3,18 & 0,45 \\
\hline Competência social & 129 & 0 & 21 & 7,82 & 2,99 & 0,71 \\
\hline Competência empreendedora & 130 & 0 & 11 & 7,11 & 2,78 & 0,65 \\
\hline Competência convencional & 129 & 0 & 11 & 3,59 & 2,80 & 0,33 \\
\hline Carreira realista & 129 & 0 & 7 & 1,89 & 1,99 & 0,16 \\
\hline Carreira investigativa & 127 & 0 & 12 & 3,57 & 2,68 & 0,30 \\
\hline Carreira artística & 130 & 0 & 50 & 4,04 & 5,23 & 0,34 \\
\hline Carreira social & 131 & 0 & 10 & 2,91 & 2,70 & 0,24 \\
\hline Carreira empreendedora & 129 & 0 & 12 & 4,27 & 3,32 & 0,36 \\
\hline Carreira convencional & 130 & 0 & 11 & 2,21 & 2,67 & 0,18 \\
\hline Habilidade realista & 131 & 1 & 7 & 3,17 & 1,77 & 0,26 \\
\hline Habilidade investigativa & 132 & 1 & 7 & 3,96 & 1,79 & 0,33 \\
\hline Habilidade artística & 132 & 1 & 7 & 3,96 & 1,94 & 0,33 \\
\hline Habilidade social & 132 & 1 & 7 & 3,85 & 1,64 & 0,32 \\
\hline Habilidade empreendedora & 132 & 1 & 7 & 3,89 & 1,78 & 0,32 \\
\hline Habilidade convencional & & 1 & 7 & 3,13 & 1,76 & 0,26 \\
\hline
\end{tabular}

Tabela 3. Correlações entre os escores da seção Competências do SDS com EAP.

\begin{tabular}{|c|c|c|c|c|c|c|c|}
\hline Dimensões & & $R$ & 1 & $A$ & $S$ & E & C \\
\hline \multirow[t]{3}{*}{ Ciências Exatas } & $r$ & 0,37 & 0,54 & $-0,02$ & $-0,02$ & 0,03 & 0,17 \\
\hline & $p$ & 0,00 & 0,00 & 0,82 & 0,84 & 0,69 & 0,05 \\
\hline & $n$ & 131 & 130 & 130 & 129 & 130 & 129 \\
\hline \multirow[t]{3}{*}{ Artes e Comunicação } & $r$ & 0,13 & 0,03 & 0,54 & 0,21 & 0,16 & 0,06 \\
\hline & $p$ & 0,13 & 0,73 & 0,00 & 0,02 & 0,07 & 0,49 \\
\hline & $n$ & 131 & 130 & 130 & 129 & 130 & 129 \\
\hline \multirow[t]{3}{*}{ Ciências Biológicas e da Saúde } & $r$ & $-0,04$ & 0,35 & 0,03 & 0,24 & $-0,03$ & $-0,07$ \\
\hline & $p$ & 0,66 & 0,00 & 0,74 & 0,00 & 0,69 & 0,42 \\
\hline & $n$ & 131 & 130 & 130 & 129 & 130 & 129 \\
\hline \multirow[t]{3}{*}{ Ciências Agrárias e Ambientais } & $r$ & 0,04 & 0,32 & 0,14 & 0,32 & 0,13 & 0,06 \\
\hline & $p$ & 0,66 & 0,00 & 0,10 & 0,00 & 0,15 & 0,49 \\
\hline & $n$ & 131 & 130 & 130 & 129 & 130 & 129 \\
\hline \multirow[t]{3}{*}{ Atividades Burocráticas } & $r$ & 0,17 & 0,20 & $-0,01$ & 0,01 & 0,29 & 0,41 \\
\hline & $p$ & 0,06 & 0,02 & 0,89 & 0,91 & 0,00 & 0,00 \\
\hline & $n$ & 131 & 130 & 130 & 129 & 130 & 129 \\
\hline \multirow[t]{3}{*}{ Ciências Humanas e Sociais } & $r$ & $-0,02$ & 0,24 & 0,32 & 0,43 & 0,21 & 0,28 \\
\hline & $p$ & 0,77 & 0,00 & 0,00 & 0,00 & 0,02 & 0,00 \\
\hline & $n$ & 131 & 130 & 130 & 129 & 130 & 129 \\
\hline \multirow[t]{3}{*}{ Entretenimento } & $r$ & 0,00 & $-0,00$ & 0,23 & 0,25 & 0,25 & 0,11 \\
\hline & $p$ & 0,98 & 0,97 & 0,00 & 0,00 & 0,00 & 0,23 \\
\hline & $n$ & 131 & 130 & 130 & 129 & 130 & 129 \\
\hline
\end{tabular}

r: coeficiente de correlação de Pearson; $p$ : nível de significância.

R: realista; I: investigativo; A: artístico; S: social; E: empreendedor; C: convencional; SDS: self-directed search carrier explorer; EAP: escala de aconselhamento profissional.

As correlações com $p \leq 0,05$ estão destacadas em negrito. 
Considerando o objetivo de estabelecer correlações entre os instrumentos, a Tabela 3 apresenta os coeficientes de correlação entre os escores da seção Competências do SDS e os escores das dimensões da EAP. As correlações foram obtidas utilizando-se o programa estatístico Statistical Package for Social Sciences (SPSS), versão 11, e para a interpretação dos valores de $r$, utilizou-se a indicação de Sisto (2007). Esse autor considera que os valores de $r$, tanto positivos quanto negativos, entre 0 e 0,20 indicam correlações nulas; entre 0,20 e 0,40, correlações baixas; entre 0,40 e 0,60, moderadas; entre 0,60 e 0,80, altas; e, por fim, valores entre 0,80 e 1 indicam correlações muito altas.

Pode-se perceber que duas correlações se destacaram: a do tipo Investigativo com a dimensão Ciências Exatas, e a do tipo Artístico com a dimensão Artes e Comunicação, ambas com coeficiente de correlação e nível de significância iguais. Além dessas, vale ressaltar também as correlações do tipo Social com a dimensão Ciências Humanas e Sociais Aplicadas ( $r=0,43$, $p<0,001)$ e do tipo Convencional com a dimensão
Atividades Burocráticas $(r=0,41, p<0,001)$. Tais resultados encontram-se, de modo geral, em consonância com os achados de Mansão (2005) ao correlacionar os tipos do SDS com o LIP, em que o tipo Investigativo (I) correlacionou-se com a área de Ciências Físicas, o tipo Artístico (A) com as áreas Artística, Linguística e Social e o tipo Convencional (C) com as áreas Burocrática Administrativa e Cálculo.

Nessa mesma direção, os resultados são coerentes quando analisados à luz da EAP; quando da análise das dimensões, os cursos de pedagogia, jornalismo, psicologia e direito foram os que obtiveram as médias maiores. Ao lado disso, nas atividades burocráticas da EAP, destacaram-se direito e administração. As correlações significativas moderadas $(r>0,40)$ de acordo com Sisto (2007) foram mais numerosas entre a seção Carreiras e as dimensões da EAP (Tabela 4).

O tipo Realista correlacionou-se com Ciências Exatas de forma moderada, embora seja diferente do encontrado na seção Competências, já que naquela a

Tabela 4. Correlações entre os escores da seção Carreiras do SDS com EAP ( $n=132)$.

\begin{tabular}{|c|c|c|c|c|c|c|c|}
\hline Dimensões & & $R$ & 1 & $A$ & S & $E$ & C \\
\hline \multirow[t]{3}{*}{ Ciências Exatas } & $r$ & 0,42 & 0,37 & $-0,02$ & $-0,10$ & 0,19 & 0,24 \\
\hline & $p$ & 0,00 & 0,00 & 0,85 & 0,23 & 0,03 & 0,01 \\
\hline & $n$ & 129 & 127 & 130 & 131 & 129 & 130 \\
\hline \multirow[t]{3}{*}{ Artes e Comunicação } & $r$ & 0,01 & 0,19 & 0,62 & 0,30 & 0,11 & $-0,14$ \\
\hline & $p$ & 0,89 & 0,03 & 0,00 & 0,00 & 0,22 & 0,10 \\
\hline & $n$ & 129 & 127 & 130 & 131 & 129 & 130 \\
\hline \multirow[t]{3}{*}{ Ciências Biológicas e da Saúde } & $r$ & 0,05 & 0,53 & 0,01 & 0,22 & $-0,08$ & $-0,11$ \\
\hline & $p$ & 0,58 & 0,00 & 0,89 & 0,01 & 0,35 & 0,20 \\
\hline & $n$ & 129 & 127 & 130 & 131 & 129 & 130 \\
\hline \multirow[t]{2}{*}{ Ciências Agrárias e Ambientais } & $r$ & 0,13 & 0,48 & 0,14 & 0,31 & 0,04 & $-0,10$ \\
\hline & $p$ & 0,14 & 0,00 & 0,12 & 0,00 & 0,67 & 0,25 \\
\hline \multirow[t]{3}{*}{ Atividades Burocráticas } & $r$ & 0,16 & 0,01 & $-0,03$ & 0,07 & 0,45 & 0,50 \\
\hline & $p$ & 0,06 & 0,92 & 0,74 & 0,43 & 0,00 & 0,00 \\
\hline & $n$ & 129 & 127 & 130 & 131 & 129 & 130 \\
\hline \multirow[t]{3}{*}{ Ciências Humanas e Sociais } & $r$ & $-0,06$ & 0,40 & 0,42 & 0,49 & 0,14 & 0,00 \\
\hline & $p$ & 0,46 & 0,00 & 0,00 & 0,00 & 0,10 & 0,97 \\
\hline & $n$ & 129 & 127 & 130 & 131 & 129 & 130 \\
\hline \multirow[t]{3}{*}{ Entretenimento } & $r$ & 0,06 & 0,11 & 0,25 & 0,43 & 0,33 & 0,14 \\
\hline & $p$ & 0,52 & 0,20 & 0,00 & 0,00 & 0,00 & 0,10 \\
\hline & $n$ & 129 & 127 & 130 & 131 & 129 & 130 \\
\hline
\end{tabular}

r: coeficiente de correlação de Pearson; $p$ : nível de significância.

R: realista; I: investigativo; A: artístico; S: social; E: empreendedor; C: convencional; SDS: self-directed search carrier explorer; EAP: escala de aconselhamento profissional. 
correlação foi baixa e os achados encontram-se em consonância com os pressupostos do SDS. Por sua vez, o tipo Investigativo foi o que apresentou o maior número de correlações significativas com Ciências Biológicas e da Saúde, Ciências Agrárias e Ambientais e com Ciências Humanas e Sociais Aplicadas. O tipo Artístico apresentou a única correlação alta $(r=0,62)$, que se deu com a dimensão Artes e Comunicação, além de uma moderada $(r=0,42)$ com Ciências Humanas e Sociais Aplicadas.

No que toca ao tipo Social, duas correlações moderadas foram encontradas, com Ciências Humanas e Sociais Aplicadas e Entretenimento. Por fim, os dois últimos tipos se correlacionaram com coeficientes acima de 0,40: Empreendedor $(0,45)$ e Convencional $(0,50)$, ambos com Atividades Burocráticas. Noronha et al. (2007) e Mansão (2005) encontraram resultados consoantes, nos quais ficaram evidenciadas as relações entre os instrumentos e os cursos profissionais no caso da EAP, e a relação entre os tipos do SDS e áreas profissionais (Tabela 5).

A seção Habilidades foi a que apresentou o menor número de correlações significativas, tal como esperado, já que dentre as seções do SDS, essa é a que mais se distancia dos pressupostos da EAP. Dentre os coeficientes significativos, merecem destaque as correlações com o tipo Artístico e a dimensão Artes e Comunicação, Social com Ciências Humanas e Sociais Aplicadas e, a exemplo do que ocorreu com a seção Carreiras, tanto Empreendedor quanto Convencional se correlacionaram com Atividades Burocráticas. Vale destacar que, apesar de essa seção apresentar menos correlações significativas, o estudo mostra-se coerente com as observações de Mansão (2005), segundo as quais o tipo Artístico (A) do SDS correlacionou-se com as áreas Artística, Linguística e Social e o tipo Social (S) com a área de Ciências Biológicas do LIP, uma vez que essa associação é encontrada em atividades profissionais que se relacionam com a ajuda ao próximo.

Tabela 5. Correlações entre os escores da seção Habilidades do SDS com EAP ( $n=132)$

\begin{tabular}{|c|c|c|c|c|c|c|c|}
\hline Dimensões & & $R$ & 1 & $A$ & S & $E$ & C \\
\hline \multirow[t]{3}{*}{ Ciências Exatas } & $r$ & 0,31 & 0,38 & $-0,08$ & $-0,12$ & 0,02 & 0,16 \\
\hline & $p$ & 0,00 & 0,00 & 0,34 & 0,17 & 0,80 & 0,07 \\
\hline & $n$ & 131 & 132 & 132 & 132 & 132 & 132 \\
\hline \multirow[t]{3}{*}{ Artes e Comunicação } & $r$ & 0,19 & $-0,15$ & 0,46 & 0,13 & $-0,06$ & $-0,02$ \\
\hline & $p$ & 0,03 & 0,09 & 0,00 & 0,13 & 0,46 & 0,78 \\
\hline & $n$ & 131 & 132 & 132 & 132 & 132 & 132 \\
\hline \multirow[t]{3}{*}{ Ciências Biológicas e da Saúde } & $r$ & 0,05 & 0,30 & $-0,03$ & 0,22 & $-0,08$ & $-0,03$ \\
\hline & $p$ & 0,56 & 0,00 & 0,74 & 0,01 & 0,34 & 0,76 \\
\hline & $n$ & 131 & 132 & 132 & 132 & 132 & 132 \\
\hline \multirow[t]{2}{*}{ Ciências Agrárias e Ambientais } & $r$ & 0,05 & 0,12 & $-0,07$ & 0,22 & 0,02 & $-0,03$ \\
\hline & $p$ & 0,57 & 0,16 & 0,39 & 0,01 & 0,85 & 0,71 \\
\hline \multirow[t]{3}{*}{ Atividades Burocráticas } & $r$ & 0,11 & 0,03 & $-0,06$ & $-0,06$ & 0,40 & 0,48 \\
\hline & $p$ & 0,21 & 0,73 & 0,50 & 0,52 & 0,00 & 0,00 \\
\hline & $n$ & 131 & 132 & 132 & 132 & 132 & 132 \\
\hline \multirow[t]{3}{*}{ Ciências Humanas e Sociais } & $r$ & $-0,11$ & 0,02 & 0,14 & 0,43 & 0,00 & 0,11 \\
\hline & $p$ & 0,21 & 0,79 & 0,12 & 0,00 & 0,97 & 0,21 \\
\hline & $n$ & 131 & 132 & 132 & 132 & 132 & 132 \\
\hline \multirow[t]{3}{*}{ Entretenimento } & $r$ & 0,09 & $-0,13$ & 0,11 & 0,21 & 0,24 & 0,17 \\
\hline & $p$ & 0,33 & 0,14 & 0,20 & 0,02 & 0,00 & 0,05 \\
\hline & $n$ & 131 & 132 & 132 & 132 & 132 & 132 \\
\hline
\end{tabular}

r: coeficiente de correlação de Pearson; $p$ : nível de significância.

R: realista; I: investigativo; A: artístico; S: social; E: empreendedor; C: convencional; SDS: self-directed search carrier explorer; EAP: escala de aconselhamento profissional.

As correlações com $p \leq 0,05$ estão destacadas em negrito. 


\section{Considerações Finais}

O estudo de instrumentos de avaliação psicológica no contexto de OP é de fundamental importância para atribuir a eles, por meio de dados empíricos, maior confiabilidade, enriquecendo assim a compreensão e a interpretação dos resultados. Além disso, ao se estudarem as relações de diferentes instrumentos, podem-se mapear as semelhanças e lacunas que seus dados indicam, proporcionando, assim, uma visão mais ampla do processo de avaliação e um planejamento mais detalhado. Nesse sentido, vale destacar a importância dos estudos com os instrumentos analisados no presente trabalho, que, em alguma medida, tendem a contribuir para a oferta de instrumentos voltados para área de OP.

O presente estudo destinou-se a analisar a relação entre dois instrumentos de avaliação de interesses profissionais: um que compreende o construto como a preferência por determinadas atividades laborais em detrimento de outras (EAP), e o segundo, em razão da relação entre interesses e características de personalidade (SDS). Embora os dois construtos sejam concordantes, eles possuem suas divergências, o que, de alguma forma, ficou revelado pelos nossos achados. As correlações encontradas revelaram a comunalidade entre os construtos, apesar de suas particularidades terem ficado reservadas.

Sendo a avaliação de interesses profissionais ainda tão incipiente no Brasil, uma pesquisa com dois instrumentos que visam medir esse construto, além de contribuir para o aprimoramento teórico na realidade nacional, auxilia também o conhecimento de características da população adolescente brasileira que, historicamente, tem sido a principal interessada em OP. Embora a amostra estudada não seja representativa a ponto de se poder generalizar seus resultados, o presente trabalho fornece dados para comparação com outros coletados em diferentes amostras, em outras regiões do Brasil. Pode-se destacar, portanto, como uma limitação do presente estudo, o fato de somente estudantes de escolas particulares terem sido pesquisados, sendo essa uma importante lacuna a ser preenchida em futuros estudos.

Outras pesquisas devem ser levadas a cabo futuramente, com esses e outros instrumentos indicados para OP. Nesse sentido, não só os interesses profissionais devem compôr o arcabouço teórico fundamental para os psicólogos que trabalham com OP, mas sua abrangência deve cobrir outros construtos também importantes para o processo de escolha, tais como: indecisão profissional, maturidade para escolha, autoeficácia e aspectos da personalidade e habilidades.

\section{Referências}

Anastasi, A., \& Urbina, S. (2000). Testagem psicológica (7a ed.). Porto Alegre: Artes Médicas.

Bueno, J. M. H., Lemos, C. G., \& Tomé, F. A. M. F. (2004). Interesses profissionais de um grupo de estudantes de psicologia e suas relações com inteligência e personalidade. Psicologia em Estudo, 9 (2), 271-278.

Gati, I. (1991). The structural of vocational interests. Psychological Bulletin, 109 (2), 309-324.

Guindon, M. H., \& Richmond, L. J. (2005). Practice and research in career counseling and development - 2004. The Career Development Quarterly, 54 (2), 90-137.

Holland, J. L. (1963). Explorations of a theory of vocational choice and achievement: II. A four-year prediction study. Psychological Reports, 12, 547-594.

Holland, J. L. (1977). Vocational indecision: more evidence and speculation. Journal of Counseling Psychology, 24, 404-414.

Holland, J. L. (1996). Exploring careers with a typology: what we have learned and some new directions. American Psychologist, 51 (4), 397-406.

Holland, J. L., Fritzsche, B. A., \& Powell, A. B. (1994). SDS- SelfDirected Search. Los Angeles, California:PAR-Psychological Assessment Resources.

Leitão, L. M., \& Miguel, J. P. (2001). Os interesses revisitados. Psychologica, 26, 79-104.

Leitão, L. M., \& Miguel, J. P. (2004). Avaliação dos Interesses. In L. M. Leitão (Org.), Avaliação psicológica em orientação escolar e profissional (pp.179-262). Coimbra: Quarteto.

Mansão, C. S. M. (2005). Interesses profissionais: validação do Self-Directed Search Career ExplorerSDS. Tese de doutorado não-publicada, Pontifícia Universidade Católica de Campinas.

Melo-Silva, L. L., Noce, M. A., \& Andrade, P.P. (2003). Interesses em adolescentes que procuram orientação profissional. Psic, 4 (2), 06-17.

Noronha, A. P. P., \& Ambiel, R. A. M. (2006). Orientação profissional e vocacional: análise da produção científica. Psico-USF, 11 (1) 75-84.

Noronha, A. P., Sisto, F., \& Santos, A. A. A. (2007). Escala de aconselhamento profissional EAP - manual técnico (Brasil). Itatiba: Vetor Editora.

Nunes, M. F. O. (2007). Escala de fontes de eficácia percebida: aplicação com jovens em escolha profissional. Dissertação de mestrado não-publicada, Universidade São Francisco, Itatiba. 
Pelletier, D., Bujold, C., \& Noiseux, G. (1985). Desenvolvimento vocacional e crescimento pessoal: enfoque operatório. Petrópolis: Vozes.

Primi, R., Moggi, M. A., \& Casellato, E. O. (2004). Estudo correlacional do inventário de busca autodirigida (SelfDirected Search) com o IFP. Psicologia Escolar e Educacional, 8 (1), 47-54.

Santos, P. J. (1997). Adolescência e indecisão vocacional. Dissertação de mestrado não-publicada, Curso de Psicologia, Universidade do Porto, Portugal.

Savickas, M. L. (1999). Examining the personal meaning of inventoried interests during career couseling. Journal of Career Assessment, 3, 188-201.

Silva, M. B. (1999). A Formação do orientador profissional. Revista Brasileira de Orientação Profissional, 3 (1), 161-165.
Sisto, F. F. (2007). Delineamento correlacional. In M. N. Baptista \& D. C. Campos. Metodologia de pesquisa em ciências: análises quantitativa e qualitativa. Rio de Janeiro: LTC.

Sparta, M. (2003). O desenvolvimento da orientação profissional no Brasil. Revista Brasileira de Orientação Profissional, 4, 1-11

Teixeira, M. A. P. \& Lassance, M. C. P. (2006). Para refletir sobre a avaliação psicológica na orientação profissional. Revista Brasileira de Orientação Profissional, 7 (2), 115-117.

Recebido em: 13/2/2008

Versão final reapresentada em: 27/5/2009

Aprovado em: 26/6/2009 